$\begin{array}{lll}\text { p1440 Eastern star: } & \begin{array}{l}\text { Singapore raises the } \\ \text { bar for biomedical } \\ \text { science in Asia. }\end{array}\end{array}$

\title{
Erythropoietin may impair, not improve, cancer survival
}

Erythropoietin (EPO), a drug commonly given to cancer patients to alleviate fatigue, may shorten survival in cancer patients and might in fact fuel tumor growth, a growing body of evidence suggests. Results from two clinical trials and various other studies could radically transform the current practice of prescribing the blockbuster drug for cancer-related anemia.

EPO is known to alleviate fatigue by stimulating red blood cell production. There was some evidence that the protein might also increase survival in anemic patients, when used with radiation and chemotherapy (J. Clin. Oncol. 19, 2865-2874; 2001). Based on that evidence, oncologists had high hopes that drugs derived from the protein would improve tumor control and survival.

In the US, pharmaceutical giant Johnson \& Johnson (J\&J) manufactures PROCRITknown as EPREX in Europe and Canada-its version of epoetin alfa, a manufactured form of the protein. Hoffman-La Roche makes NeoRecormon or epoetin beta, another variant of the protein. To test whether EPO would improve patient survival, the companies launched a number of investigational clinical trials. But the results thus far have been completely unexpected.

In August, J\&J's Breast Cancer Erythropoietin Trial (BEST) in nonanemic patients was terminated early when researchers discovered a higher mortality rate in the EPO group than in those taking the placebo (Lancet Oncol. 4, 459-460; 2003). More recently, a Hoffman-La Roche trial in head-and-neck cancer patients found that epoetin beta also had adverse effects on survival, this time in anemic patients (Lancet 362, 1255-1260; 2003).

The results "were contrary to what we were expecting," says Michael Henke, lead investigator of the epoietin beta trial and vice chairman of radiation oncology at the University of Freiburg in Germany. "I would now have trouble giving EPO to patients undergoing curative therapy, on the basis of these and a number of unpublished trials."

EPO stimulates red blood cell production by attaching to receptors on those cells. But there is mounting evidence that some nonhematopoietic cells also carry EPO receptors. Research in
Japan suggests that many cancer cell types use the EPO system for growth and angiogenesis (Carcinogenesis 24, 1021-1029; 2003).

Henke has found that more than $80 \%$ of head-and-neck cancer patients have tumors that express EPO receptors. There is evidence that breast cancer cells also express EPO and functional EPO receptors (Cancer Res. 61, 3561-3565; 2001; Blood 98, 300-301a; 2001). Recent studies from Harvard University researchers Laurie Feldman and Arthur Sytkowski also suggest that EPO receptors are expressed in the female reproductive tract and in the developing heart and brain.

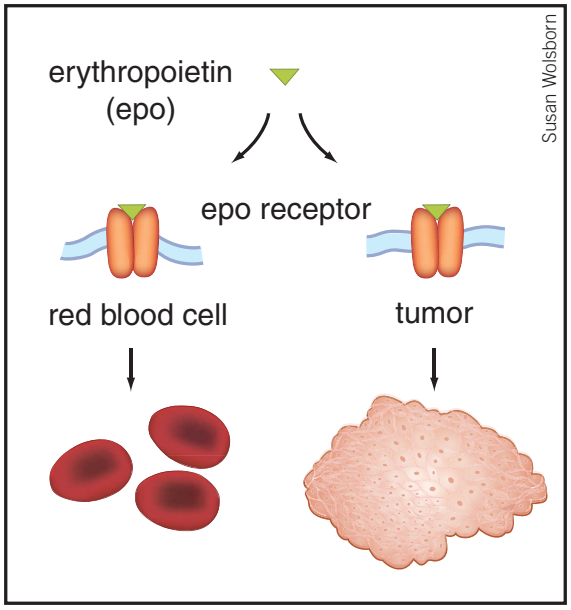

These facts alone warrant a closer look at using EPO in cancer patients, says Feldman, assistant professor of medicine at Harvard. Feldman and colleagues have presented evidence that prostate and ovarian cancer cells possess EPO receptors, and that these cells proliferate in response to the protein. Feldman discovered EPO receptors on prostate epithelial cells that are transformed but not yet cancerous, on various cultured prostate cancer cell lines and on normal prostate cells. She tested the three cell types with EPO, and found that all grew faster in a dose-dependent manner.

More recently, Feldman and Sytkowski discovered that when ovarian cancer cells expressing EPO receptors are treated with EPO for two months and then with paclitaxel — the active ingredient in TAXOL-the cancer cells become paclitaxel-resistant and survive longer than non-EPO-treated cells. The EPO-treated cells also had decreased levels of the antiapoptotic protein Bcl-2.

Henke's most recent research shows that EPO affects the apoptotic pathway, which would explain its effect in stimulating red blood cell production. The problem is that the same effect might help tumor cells survive and grow.

Following Nature Medicine's inquiry into the results, Feldman, Sytkowski and Henke spoke to each other for the first time. Although observed as a clinical problem, the results seem to be based on a biological phenomenon, they now say. "This clearly means coming from bedside and getting back to bench," says Henke.

The new results could spell bad news for companies such as J\&J, Amgen and HoffmanLa Roche. An estimated 300,000 patients take EPO each year, and sales for PROCRIT alone surpassed $\$ 3$ billion last year.

J\&J and Hoffman-La Roche maintain that their drugs are safe. Although their trial results "do not support" the use of EPO as an adjunct therapy for head-and-neck cancer, says Andrew Loop, Hoffman-La Roche's medical director, there were too many "confounding factors and baseline imbalances" in the trial to draw any conclusions about the drug's survival benefits. The company has other such trials in progress.

J\&J is also monitoring survival in its ongoing trials, says Mark Wolfe, director of public affairs at Ortho Biotech, which markets PROCRIT for J\&J. Wolfe says PROCRIT is safe for treating anemic cancer patients. But, "we have seen, in the treatment of nonanemic patients with EPO, a rise in side effects," Wolfe says. "For this reason, we are not sponsoring trials in this area."

Asked about Hoffman-La Roche's trial results with anemic patients, Wolfe says results with epoetin alfa and epoetin beta cannot be considered together. "Our drug and their drug are two different drugs," he says. However, other researchers, including Henke, say the differences between the two variants are minor.

"Companies developed an oncology market based on EPO's ability to treat fatigue," says Henke. "My study can only be making these companies nervous."

Vicki Brower, New York 